\title{
Long-Term Survival Among Histological Subtypes in Advanced Epithelial Ovarian Cancer: Population-Based Study Using the Surveillance, Epidemiology, and End Results Database
}

Shi-Ping Yang ${ }^{1 *}$, MD; Hui-Luan Su${ }^{2 *}$, MD; Xiu-Bei Chen ${ }^{3 *}$, MD; Li Hua ${ }^{4}$, MD; Jian-Xian Chen ${ }^{5}$, MD; Min Hu , MD; Jian Lei ${ }^{4}$, MD; San-Gang $\mathrm{Wu}^{3}$, MD; Juan Zhou ${ }^{4}$, MD

\footnotetext{
${ }^{1}$ Department of Radiation Oncology, Hainan General Hospital (Hainan Affiliated Hospital of Hainan Medical University), Haikou, China

${ }^{2}$ Department of Nephrology, Hainan General Hospital (Hainan Affiliated Hospital of Hainan Medical University), Haikou, China

${ }^{3}$ Department of Radiation Oncology, The First Affiliated Hospital of Xiamen University, Xiamen, China

${ }^{4}$ Department of Obstetrics and Gynecology, The First Affiliated Hospital of Xiamen University, Xiamen, China

${ }^{5}$ Department of Medical Oncology, People's Hospital of Baise, Baise, China

*these authors contributed equally
}

\section{Corresponding Author:}

Juan Zhou, MD

Department of Obstetrics and Gynecology

The First Affiliated Hospital of Xiamen University

55 Zhenhai Road

Xiamen, 361003

China

Phone: 865922139531

Email: zhoujuan@xmu.edu.cn

\section{Abstract}

Background: Actual long-term survival rates for advanced epithelial ovarian cancer (EOC) are rarely reported.

Objective: This study aimed to assess the role of histological subtypes in predicting the prognosis among long-term survivors ( $\geq 5$ years) of advanced EOC.

Methods: We performed a retrospective analysis of data among patients with stage III-IV EOC diagnosed from 2000 to 2014 using the Surveillance, Epidemiology, and End Results cancer data of the United States. We used the chi-square test, Kaplan-Meier analysis, and multivariate Cox proportional hazards model for the analyses.

Results: We included 8050 patients in this study, including 6929 (86.1\%), 743 (9.2\%), 237 (2.9\%), and 141 (1.8\%) patients with serous, endometrioid, clear cell, and mucinous tumors, respectively. With a median follow-up of 91 months, the most common cause of death was primary ovarian cancer $(80.3 \%)$, followed by other cancers $(8.1 \%)$, other causes of death (7.3\%), cardiac-related death $(3.2 \%)$, and nonmalignant pulmonary disease (3.2\%). Patients with the serous subtype were more likely to die from primary ovarian cancer, and patients with the mucinous subtype were more likely to die from other cancers and cardiac-related disease. Multivariate Cox analysis showed that patients with endometrioid (hazard ratio [HR] 0.534, $P<.001$ ), mucinous (HR 0.454, $P<.001$ ), and clear cell (HR 0.563, $P<.001$ ) subtypes showed better ovarian cancer-specific survival than those with the serous subtype. Similar results were found regarding overall survival. However, ovarian cancer-specific survival and overall survival were comparable among those with endometrioid, clear cell, and mucinous tumors.

Conclusions: Ovarian cancer remains the primary cause of death in long-term ovarian cancer survivors. Moreover, the probability of death was significantly different among those with different histological subtypes. It is important for clinicians to individualize the surveillance program for long-term ovarian cancer survivors.

(JMIR Public Health Surveill 2021;7(11):e25976) doi: 10.2196/25976

\section{KEYWORDS}

ovarian epithelial carcinoma; survivors; histology; survival rate; survival; ovarian; cancer; surveillance; epidemiology; women's health; reproductive health; Surveillance, Epidemiology, and End Results; ovary; oncology; survivorship; long-term outcome; epithelial 


\section{Introduction}

\section{Background}

Advanced stage (stage III-IV) epithelial ovarian cancer (EOC) is usually incurable. However, approximately $25 \%$ and $15 \%$ of patients with EOC survive for $>5$ years and $>10$ years, respectively [1-4]. Although it largely remains unknown why long-term survivors have a better outcome, investigating the underlying mechanisms or factors is key for developing individualized follow-up strategies for patients with EOC. Several epidemiological, clinical, and genetic factors have been associated with the long-term survival of patients with EOC $[5,6]$.

Based on the World Health Organization classification of tumors of female reproductive organs, which was published in 2014, EOC can be classified into five histological subtypes: high-grade serous, low-grade serous, endometrioid, clear cell, and mucinous [7]. A previous study using the California Cancer Registry reported that the nonserous subtype is an independent predictor of long-term survival in EOC; favorable prognoses were observed among patients with the endometrioid, mucinous, and clear cell subtypes than in those with the serous subtype [3]. However, the same study also included patients with early-stage EOC, and it may thus not reflect the true long-term survival characteristics of patients with advanced-stage EOC.

The endometrioid and mucinous subtypes are typically low-grade and early-stage, and patients with these subtypes show a better outcome than those with the high-grade serous subtype [8-10]. Moreover, although the clear cell subtype exhibits high-grade features, it is more likely to present with early-stage disease and is associated with a better outcome than high-grade serous cancers [11]. However, several studies, including ours, have confirmed that advanced mucinous and clear cell cancers display aggressive behavior, and patients with these have lower survival than those with high-grade serous tumors, which can perhaps be attributed to chemoresistance characteristics [12-18]. Accordingly, this study aimed to assess the role of histological subtypes in predicting the prognosis of long-term survivors ( $\geq 5$ years) of advanced EOC.

\section{Methods}

We extracted EOC data from the Surveillance, Epidemiology, and End Results (SEER) database of the United States, which is a publicly available database and contains deidentified information on cancer incidence, demographic and clinicopathological variables, patterns of the first course of treatment, and survival data [19]. We selected patients of all ages who were diagnosed with stage III-IV EOC from 2000 to 2014. We included long-term ovarian cancer survivors $(\geq 5$ years) in this study. The patient selection flowchart is shown in Figure 1. We included those with high-grade serous, endometrioid, clear cell, and mucinous subtypes. Patients who did not undergo any surgery or did not receive chemotherapy were excluded. In addition, patients who died within 60 months after the diagnosis of ovarian cancer or who had follow-up times of $<60$ months were also excluded. The analysis of the SEER database was exempt from the approval process of the institutional review board considering the presence of deidentified patient information.

A total of 29,176 patients with stage III-IV EOC were identified. Of these patients, 5857 did not receive chemotherapy, 251 patients had a follow-up time of $<60$ months, 14,866 patients died within 60 months, and 152 patients did not receive surgery. A total of 8050 EOC patients with $\geq 5$ years' survival were included in this study.

This study could be used to assist physicians in prognostic assessment at the time of diagnosis of EOC and help physicians better understand EOC from the long-term survivors to prolong the survival time of short-term survivors. The SEER program collects long-term follow-up cancer data, thus allowing us to assess the long-term survivors of EOC. We included the following demographic, clinicopathological, and treatment variables: age at diagnosis, race, stage, histological subtype, and nodal status. The definition of the staging system was based on the American Joint Committee on Cancer (AJCC) sixth edition staging system. The primary endpoints of this study were ovarian cancer-specific survival (OCSS) and overall survival (OS). OCSS was defined as the time from diagnosis to death due to ovarian cancer, censoring at the date of last contact, or nonovarian cancer related-death. OS was defined as the time from diagnosis of ovarian cancer to the death from any cause.

The association among demographic, clinicopathological, and treatment variables for the histological subtypes was compared using the chi-square test and the Fisher exact test. Survival comparisons were made using Kaplan-Meier analysis and compared using the log-rank test. Multivariate Cox proportional hazards model was used to determine the prognostic factors associated with OCSS and OS. Prognostic factors with statistical significance on univariate analyses were entered into multivariate analyses. The proportional hazard assumption was tested both graphically and using the Schoenfield residual test to address whether our data met the proportional odds assumption, allowing for the use of the Cox proportional hazards model. Sensitivity analyses were performed on the basis of the age at diagnosis, race, AJCC staging, and nodal status to investigate the effect of the histological subtype on survival outcomes. SPSS (version 22.0, IBM Corp) and Stata/SE (version 14 , StataCorp) were used for analyses, and $P<.05$ indicated statistical significance. 
Figure 1. Flow diagram of the study cohort.

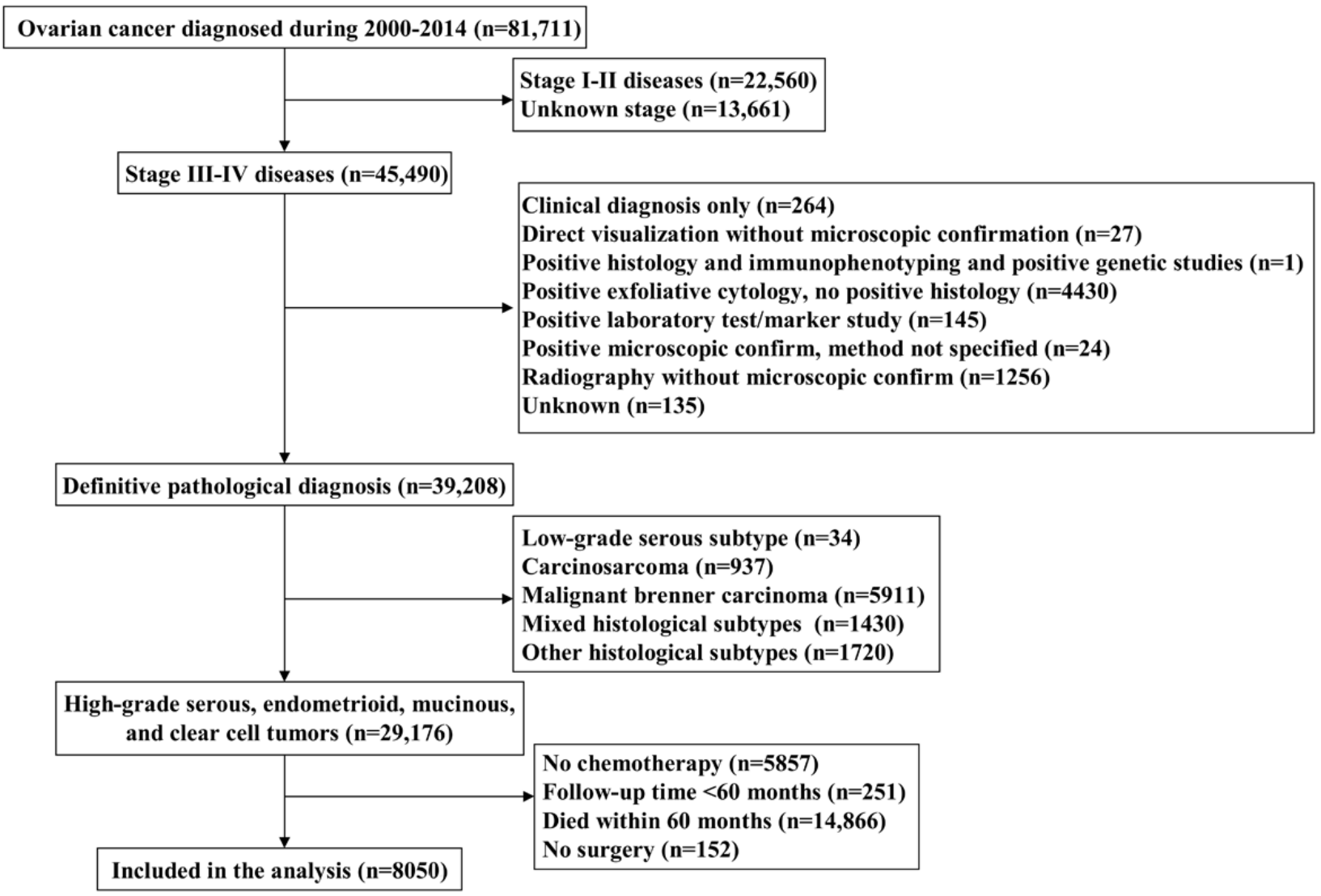

\section{Results}

\section{Patient Characteristics}

Patient characteristics and causes of death data are listed in Table 1. Of the entire cohort, $6929(86.1 \%), 743(9.2 \%), 237$ $(2.9 \%)$, and $141(1.8 \%)$ showed the presence of serous, endometrioid, clear cell, and mucinous tumors, respectively. The majority of patients were aged $\geq 50$ years $(76.8 \%, \mathrm{n}=6138)$, white race $(86.6 \%, \mathrm{n}=6975)$, stage III disease $(75.6 \%, \mathrm{n}=6164)$, and nodal negative disease $(57.8 \%, \mathrm{n}=4651)$. Patients with the serous subtype were more likely to be older $(P<.001)$ and diagnosed with stage IV disease $(P<.001)$ than those with the other 3 histological subtypes. In addition, patients with the serous subtype had a higher risk of regional lymph node metastasis than those with the endometrioid and mucinous subtypes (35.7\% vs $26.2 \%-31.5 \%$ ), while those with the clear cell subtype had a higher risk of regional lymph node metastasis than those with the other 3 histological subtypes (42.6\% vs $26.2 \%-35.7 \%)(P<.001)$. 
Table 1. Baseline patient characteristics and causes of death by histological subtype in patients with epithelial ovarian cancer diagnosed from 2000 to 2014 using the Surveillance, Epidemiology, and End Results cancer data of the United States.

\begin{tabular}{|c|c|c|c|c|c|c|}
\hline Variables & Patients, $\mathrm{n}$ & Serous subtype, $\mathrm{n}(\%)$ & $\begin{array}{l}\text { Endometrioid sub- } \\
\text { type, } \mathrm{n}(\%)\end{array}$ & $\begin{array}{l}\text { Mucinous subtype, } \mathrm{n} \\
(\%)\end{array}$ & $\begin{array}{l}\text { Clear cell subtype, } \mathrm{n} \\
(\%)\end{array}$ & $P$ value \\
\hline Age (years) & & & & & & $<.001$ \\
\hline$<50$ & 1867 & $1528(22.1)$ & $231(31.1)$ & $51(36.2)$ & $57(24.1)$ & \\
\hline $50-64$ & 3662 & $3146(45.4)$ & $323(43.5)$ & $64(45.4)$ & $129(54.4)$ & \\
\hline$\geq 65$ & 2521 & $2255(32.5)$ & $189(25.4)$ & $26(18.4)$ & $51(21.5)$ & \\
\hline Race & & & & & & $<.001$ \\
\hline White & 6975 & $6037(87.1)$ & $616(82.9)$ & $124(87.9)$ & $198(83.5)$ & \\
\hline Black & 420 & $371(5.4)$ & $41(5.5)$ & $3(2.1)$ & $5(2.1)$ & \\
\hline Other & 655 & $521(7.5)$ & $86(11.6)$ & $14(9.9)$ & $34(14.3)$ & \\
\hline \multicolumn{6}{|c|}{ American Joint Committee on Cancer stage } & $<.001$ \\
\hline III & 6164 & $5235(75.6)$ & $629(84.7)$ & $113(80.1)$ & $187(78.9)$ & \\
\hline IV & 1886 & $1694(24.4)$ & $114(15.3)$ & $28(19.9)$ & $50(21.1)$ & \\
\hline Nodal status & & & & & & $<.001$ \\
\hline Negative & 4651 & $3954(57.1)$ & $477(64.2)$ & $99(70.2)$ & $121(51.1)$ & \\
\hline Positive & 2849 & $3477(35.7)$ & $234(31.5)$ & $37(26.2)$ & $101(42.6)$ & \\
\hline Unknown & 550 & $498(7.2)$ & $32(4.3)$ & $5(3.5)$ & $15(6.3)$ & \\
\hline Death $(n=3874)$ & & & & & & $<.001$ \\
\hline Primary ovarian cancer & 3111 & $2819(81.8)$ & $199(68.4)$ & $33(61.1)$ & $60(73.2)$ & \\
\hline Other cancers & 312 & $266(7.7)$ & $37(12.7)$ & $7(13.0)$ & $2(2.4)$ & \\
\hline Cardiac death & 123 & $96(2.8)$ & $12(4.1)$ & $9(16.7)$ & $6(7.3)$ & \\
\hline Pulmonary deaths & 44 & $36(1.0)$ & $2(0.7)$ & $1(1.9)$ & $5(6.1)$ & \\
\hline Other causes & 284 & $230(6.7)$ & $41(14.1)$ & $4(7.4)$ & $9(11.0)$ & \\
\hline
\end{tabular}

\section{Causes of Death in Long-Term Ovarian Cancer Survivors}

This cohort included 5967 patients surviving for $\geq 5$ years and $<10$ years (60-119 months) and 2353 patients surviving $\geq 10$ years ( $\geq 120$ months). With a median follow-up of 91 (range 60-227) months, a total of 3874 deaths were recorded. The most common cause of death was primary ovarian cancer $(80.3 \%$, $\mathrm{n}=3111)$, followed by other cancers $(8.1 \%, \mathrm{n}=312)$, other causes of death $(7.3 \%, n=284)$, cardiac-related death $(3.2 \%, n=123)$, and nonmalignant pulmonary disease (3.2\%). Patients with the serous subtype were more likely to die from primary ovarian cancer, and those with the mucinous subtype were more likely to die from other cancers and cardiac-related disease (Table 1). Among those surviving $\geq 5$ years and $<10$ years, $83.3 \%$ died owing to primary ovarian cancer, $7.4 \%$ died owing to other cancers, $6.0 \%$ died owing to other causes, $2.4 \%$ died owing to cardiac disease, and $0.9 \%$ died owing to nonmalignant pulmonary disease. For patients surviving $\geq 10$ years, $63.0 \%$ died owing to primary ovarian cancer, $14.9 \%$ died owing to other causes, $12.1 \%$ died owing to other cancers, $7.7 \%$ died owing to cardiac disease, and $2.3 \%$ died owing to nonmalignant pulmonary disease.

The causes of death after stratification by years of survival after diagnosis of EOC for long-term survivors are detailed in Figure 2. Figure $2 \mathrm{~A}$ shows that in the entire cohort, with an increase in the time from diagnosis, death because of ovarian cancer-related causes decreases, while death owing to cardiac disease and other causes increases. In patients aged $<50$ years and 50-64 years, death due to ovarian cancer-related disease remained the main cause of death with an increase in the time from diagnosis, and death from primary ovarian cancer was still significant among other causes of death even 15 years after diagnosis of ovarian cancer (Figure 2B and 2C). Among those aged $\geq 65$ years, death because of ovarian cancer-related causes decreased and death due to cardiac disease and other causes increased (Figure 2D). 
Figure 2. Causes of death after stratification by years of survival after diagnosis of epithelial ovarian cancer for long-term survivors: (A) the entire cohort; (B) patients aged <50 years; (C) patients aged 50-64 years; and (D) patients aged $\geq 65$ years.

\section{A. Causes of death across different periods}

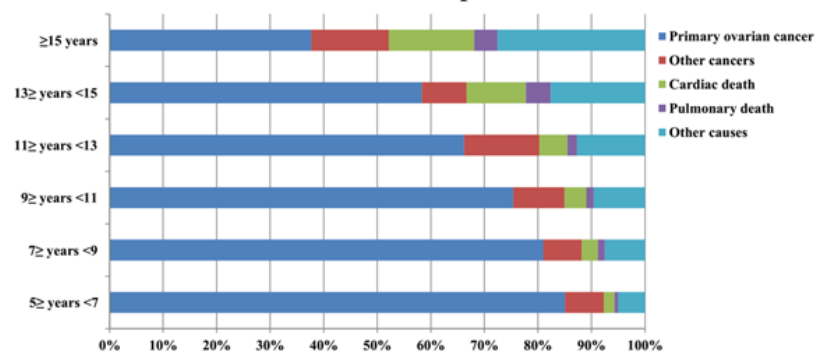

C. Causes of death among patients aged 50-64 years

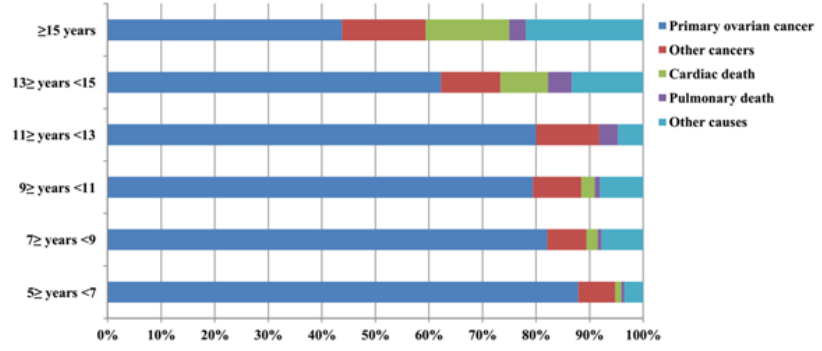

\section{Survival Outcomes and Prognostic Analyses}

Kaplan-Meier analysis was conducted to compare the survival curves among the 4 histological subtypes (Figure 3 ). The results showed that serous subtype had a significantly lower OCSS $(P<.001)$ and OS $(P<.001)$ compared to those with the other 3 histological subtypes, while comparable OCSS $(P=.55)$ (Figure $3 \mathrm{~A})$ and $\mathrm{OS}(P=.91)$ (Figure $3 \mathrm{~B})$ were observed among those with endometrioid, mucinous, and clear cell cancers.

Univariate and multivariate analyses were used to determine the prognostic factors related to OCSS and OS. Univariate analyses showed that age at diagnosis, AJCC staging, nodal status, and histological subtype were the prognostic factors associated with OCSS and OS (Tables 2 and 3). The results showed that age at diagnosis, AJCC staging, nodal status, and histological subtype were also the independent prognostic factors associated with OCSS and OS. Patients with endometrioid (hazard ratio [HR] $0.534,95 \%$ CI $0.462-0.617, P<.001$ ), mucinous (HR $0.454,95 \%$ CI $0.322-0.641, P<.001$ ), and clear cell (HR $0.563,95 \%$ CI $0.436-0.727, P<.001$ ) subtypes showed better OCSS than those with the serous subtype. Similar results were obtained regarding OS. Using clear cell tumor as a reference, similar OCSS and OS were observed in endometrioid (OCSS: HR 0.949, 95\% CI 0.711-1.267, $P=.72$; OS: HR 1.014, 95\% CI 0.793-1.295, $P=.91$ ) and mucinous cancers (OCSS: HR $0.807,95 \%$ CI $0.528-1.235, P=.32$; OS: HR $0.969,95 \%$ CI

\section{B. Causes of death among patients aged $<50$ years}

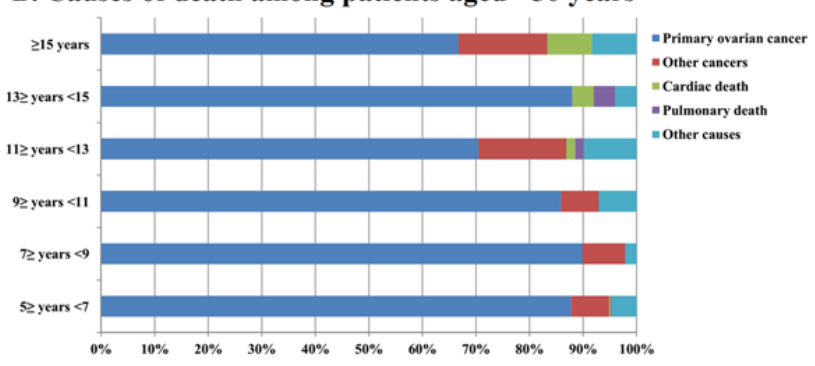

D. Causes of death among patients aged $\geq 65$ years

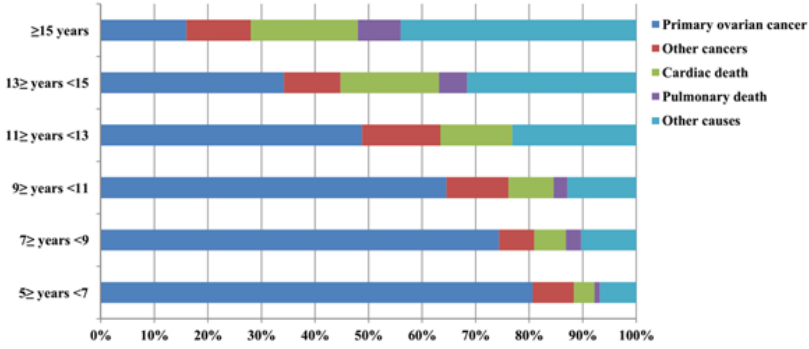

0.687-1.366, $P=.86)$ compared to those with clear cell tumor. The effect of the histological subtype on OCSS (Figure 4A) and OS (Figure 4B) met the proportional hazard assumption, which showed that the constant HRs from the Cox model were reliable.

Since we observed similar survival outcomes among patients with endometrioid, mucinous, and clear cell cancers, we combined these histological subtypes under the nonserous subtype to compare the survival outcomes with those of serous cancers. Kaplan-Meier analysis showed that patients with the serous subtype had a significantly lower OCSS $(P<.001)$ (Figure $5 \mathrm{~A})$ and $\mathrm{OS}(P<.001)$ (Figure $5 \mathrm{~B})$ than those with nonserous tumors.

Sensitivity analyses were focused on age at diagnosis, race, AJCC staging, and nodal status to investigate the effect of histology on survival outcomes (Table 4). The obtained results indicated that patients with the serous subtype had lower OCSS and OS than those with the nonserous subtype, stratified by age at diagnosis, stage at diagnosis, and nodal stage. Among White patients and those of other races, the serous subtype was characterized with lower OCSS and OS than the nonserous subtype. Between the serous and nonserous subtypes, the OCSS and OS were comparable among Black patients. The effect of the histology on OCSS (Figure 4C) and OS (Figure 4D) met the proportional hazard assumption, which indicated that the constant HRs ratios from the Cox model were reliable. 
Figure 3. Comparison of ovarian cancer-specific survival (A) and overall survival (B) among the 4 histological subtypes of the epithelial ovarian cancer diagnosed from 2000 to 2014 using the Surveillance, Epidemiology, and End Results cancer data of the United States.

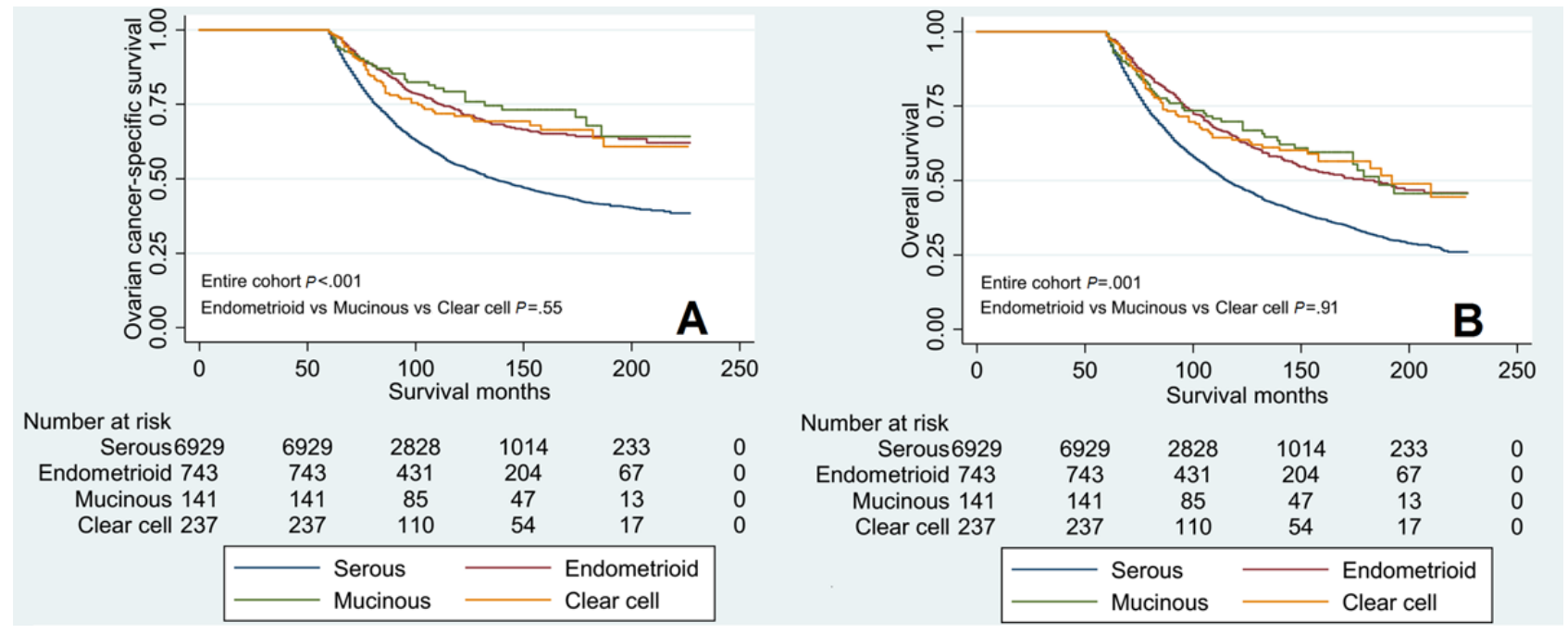

Table 2. Univariate and multivariate survival analyses of ovarian cancer-specific survival in long-term survivors of the epithelial ovarian cancer diagnosed from 2000 to 2014 using the Surveillance, Epidemiology, and End Results cancer data of the United States.

\begin{tabular}{|c|c|c|c|c|}
\hline \multirow[t]{2}{*}{ Variables } & \multicolumn{2}{|c|}{ Univariate survival analysis } & \multicolumn{2}{|c|}{ Multivariate survival analysis } \\
\hline & Hazard ratio $(95 \% \mathrm{CI})$ & $P$ value & Hazard ratio $(95 \% \mathrm{CI})$ & $P$ value \\
\hline \multicolumn{5}{|l|}{ Age (years) } \\
\hline$<50$ & 1 (reference) & Reference & 1 (reference) & Reference \\
\hline $50-64$ & $1.137(1.037-1.246)$ & .006 & $1.091(0.995-1.196)$ & .06 \\
\hline$\geq 65$ & $1.457(1.323-1.606)$ & $<.001$ & $1.361(1.234-1.500)$ & $<.001$ \\
\hline \multicolumn{5}{|l|}{ Race } \\
\hline White & 1 (reference) & Reference & $-^{\mathrm{a}}$ & - \\
\hline Black & $0.949(0.804-1.119)$ & .53 & - & - \\
\hline Other & $0.913(0.797-1.044)$ & .18 & - & - \\
\hline \multicolumn{5}{|c|}{ American Joint Committee on Cancer stage } \\
\hline III & 1 (reference) & Reference & 1 (reference) & Reference \\
\hline IV & $1.355(1.252-1.467)$ & $<.001$ & $1.224(1.125-1.333)$ & $<.001$ \\
\hline \multicolumn{5}{|l|}{ Nodal status } \\
\hline Negative & 1 (reference) & Reference & 1 (reference) & Reference \\
\hline Positive & $0.847(0.784-0.916)$ & $<.001$ & $0.844(0.781-0.912)$ & $<.001$ \\
\hline Unknown & $1.511(1.339-1.705)$ & $<.001$ & $1.309(1.149-1.490)$ & $<.001$ \\
\hline \multicolumn{5}{|c|}{ Histological subtypes } \\
\hline Serous & 1 (reference) & Reference & 1 (reference) & Reference \\
\hline Endometrioid & $0.515(0.446-0.595)$ & $<.001$ & $0.534(0.462-0.617)$ & $<.001$ \\
\hline Mucinous & $0.436(0.309-0.615)$ & $<.001$ & $0.454(0.322-0.641)$ & $<.001$ \\
\hline Clear cell & $0.550(0.426-0.711)$ & $<.001$ & $0.563(0.436-0.727)$ & $<.001$ \\
\hline
\end{tabular}

a_: not determined. 
Table 3. Univariate and multivariate survival analyses of overall survival among long-term survivors of the epithelial ovarian cancer diagnosed from 2000 to 2014 using the Surveillance, Epidemiology, and End Results cancer data of the United States.

\begin{tabular}{|c|c|c|c|c|}
\hline \multirow[t]{2}{*}{ Variables } & \multicolumn{2}{|c|}{ Univariate survival analysis } & \multicolumn{2}{|c|}{ Multivariate survival analysis } \\
\hline & Hazard ratio $(95 \% \mathrm{CI})$ & $P$ value & Hazard ratio $(95 \% \mathrm{CI})$ & $P$ value \\
\hline \multicolumn{5}{|l|}{ Age (years) } \\
\hline$<50$ & 1 (reference) & Reference & 1 (reference) & Reference \\
\hline $50-64$ & $1.188(1.091-1.293)$ & $<.001$ & $1.149(1.055-1.251)$ & .001 \\
\hline$\geq 65$ & $1.763(1.615-1.924)$ & $<.001$ & $1.668(1.527-1.821)$ & $<.001$ \\
\hline \multicolumn{5}{|l|}{ Race } \\
\hline White & 1 (reference) & Reference & $-^{\mathrm{a}}$ & - \\
\hline Black & $0.970(0.838-1.123)$ & .69 & - & - \\
\hline Other & $0.916(0.812-1.034)$ & .16 & - & - \\
\hline \multicolumn{5}{|c|}{ American Joint Committee on Cancer stage } \\
\hline III & 1 (reference) & Reference & 1 (reference) & Reference \\
\hline IV & $1.349(1.257-1.448)$ & $<.001$ & $1.222(1.132-1.319)$ & $<.001$ \\
\hline \multicolumn{5}{|l|}{ Nodal status } \\
\hline Negative & 1 (reference) & Reference & 1 (reference) & Reference \\
\hline Positive & $0.853(0.796-0.915)$ & $<.001$ & $0.863(0.805-0.925)$ & $<.001$ \\
\hline Unknown & $1.484(1.330-1.655)$ & $<.001$ & $1.298(1.154-1.459)$ & $<.001$ \\
\hline \multicolumn{5}{|c|}{ Histological subtypes } \\
\hline Serous & 1 (reference) & Reference & 1 (reference) & Reference \\
\hline Endometrioid & $0.601(0.533-0.677)$ & $<.001$ & $0.632(0.561-0.713)$ & $<.001$ \\
\hline Mucinous & $0.566(0.432-0.740)$ & $<.001$ & $0.604(0.461-0.791)$ & $<.001$ \\
\hline Clear cell & $0.606(0.487-0.754)$ & $<.001$ & $0.624(0.501-0.776)$ & $<.001$ \\
\hline
\end{tabular}

a_: not determined. 
Figure 4. The evaluation of the proportional hazards assumption in ovarian cancer-specific survival (A and C) and overall survival (B and D) among the different histological subtypes of the epithelial ovarian cancer from 2000 to 2014 using the Surveillance, Epidemiology, and End Results cancer data of the United States.
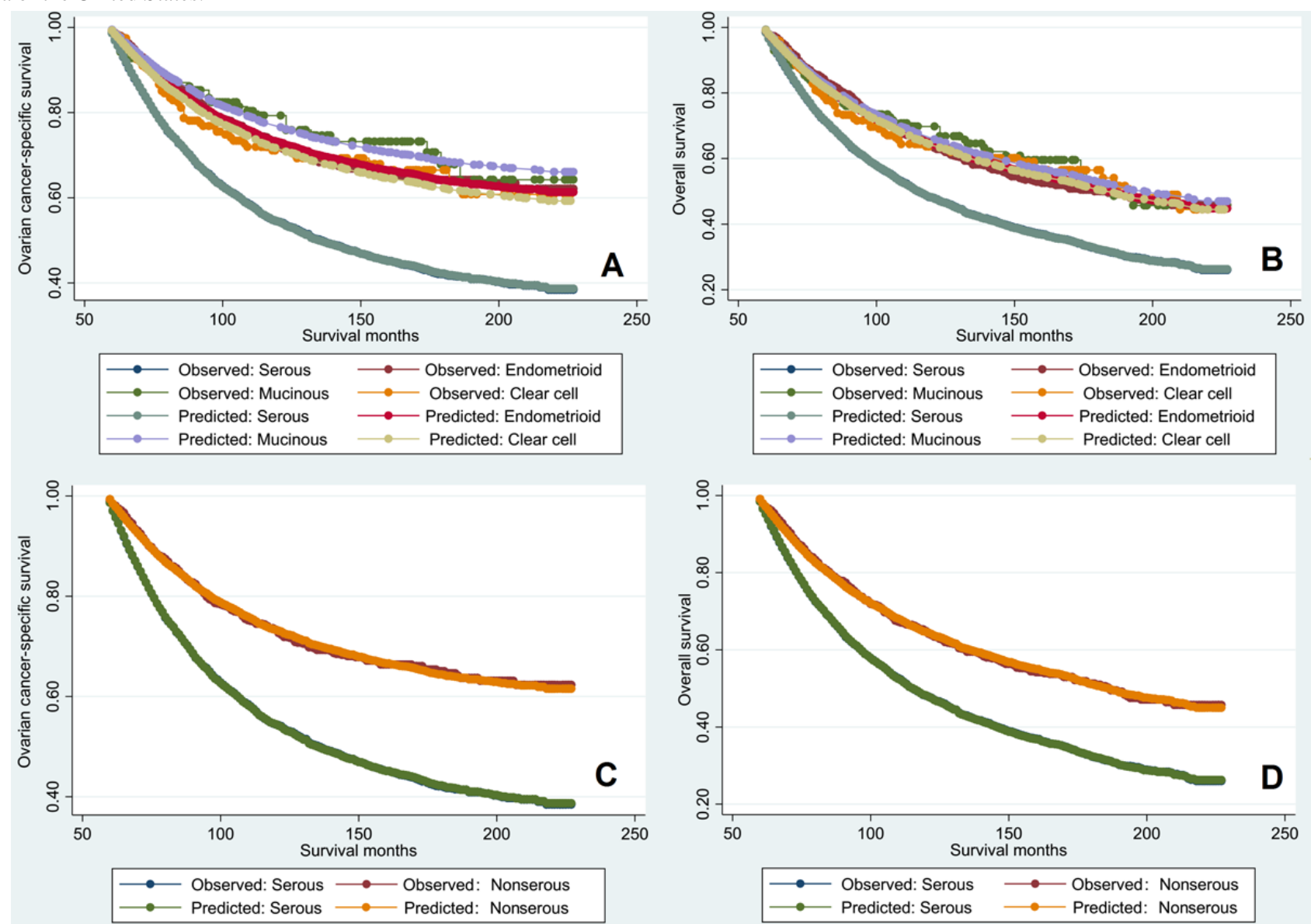

Figure 5. Ovarian cancer-specific survival curves (A) and overall survival curves (B) between serous cancer and non-serous cancer from 2000 to 2014 using the Surveillance, Epidemiology, and End Results cancer data of the United States.

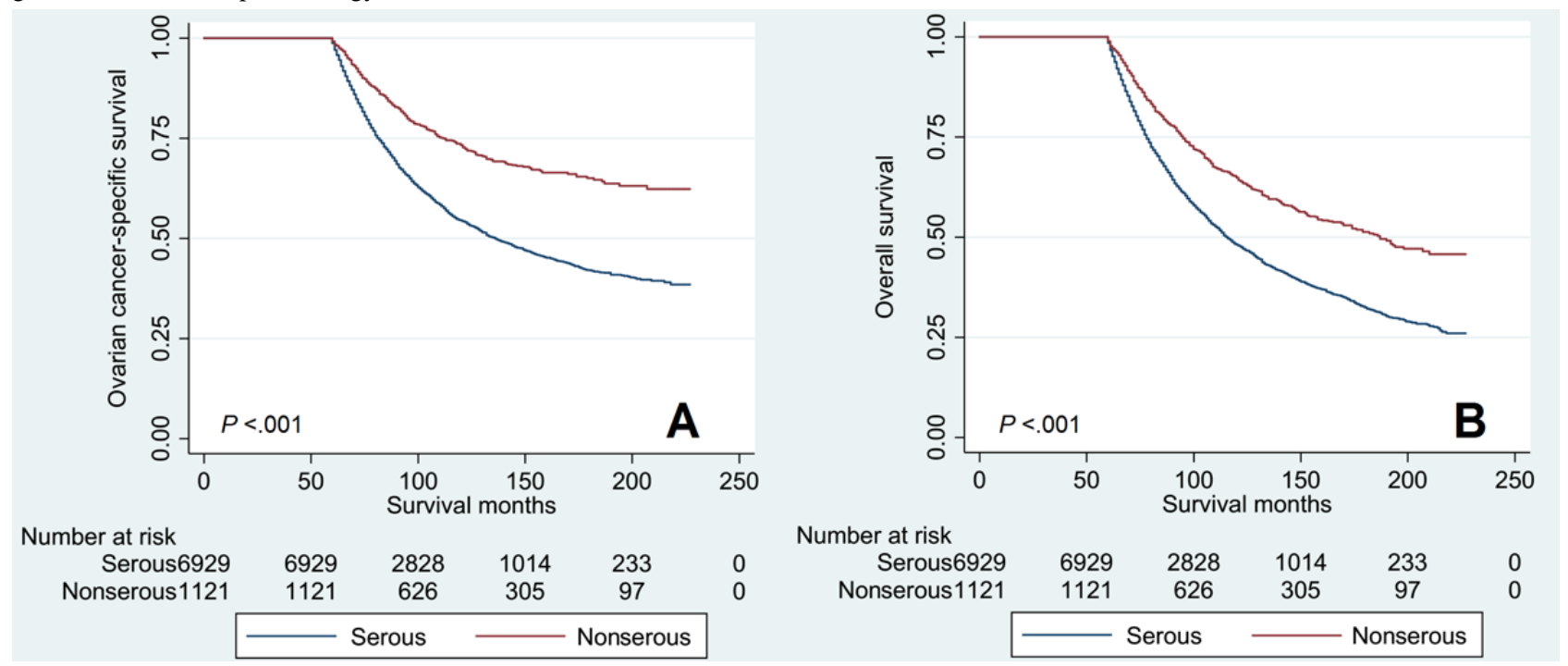


Table 4. Stratified analyses of the multivariable-adjusted hazard ratios and $95 \%$ CIs for ovarian cancer-specific survival and overall survival by histological subtype (serous vs nonserous) among long-term survivors of the epithelial ovarian cancer diagnosed from 2000 to 2014 using the Surveillance, Epidemiology, and End Results cancer data of the United States.

\begin{tabular}{|c|c|c|c|c|}
\hline \multirow[t]{2}{*}{ Variables (serous vs nonserous) } & \multicolumn{2}{|c|}{ Ovarian cancer-specific survival } & \multicolumn{2}{|l|}{ Overall survival } \\
\hline & Hazard ratio $(95 \% \mathrm{CI})$ & $P$ value & Hazard ratio $(95 \% \mathrm{CI})$ & $P$ value \\
\hline Aged $<50$ years & $2.381(1.861-3.046)$ & $<.001$ & $2.088(1.679-2.596)$ & $<.001$ \\
\hline Aged $50-64$ years & $1.809(1.514-2.161)$ & $<.001$ & $1.516(1.304-1.763)$ & $<.001$ \\
\hline Aged $\geq 65$ years & $1.636(1.311-2.041)$ & $<.001$ & $1.414(1.188-1.683)$ & $<.001$ \\
\hline Black patients & $1.383(0.799-2.395)$ & .25 & $1.088(0.692-1.712)$ & .72 \\
\hline Patients of other race & $3.672(2.294-5.879)$ & $<.001$ & $2.276(1.609-3.219)$ & $<.001$ \\
\hline American Joint Committee on Cancer stage III disease & $1.715(1.503-1.958)$ & $<.001$ & $1.507(1.347-1.684)$ & $<.001$ \\
\hline American Joint Committee on Cancer stage IV disease & $2.861(2.102-3.894)$ & $<.001$ & $1.990(1.575-2.515)$ & $<.001$ \\
\hline Nodal positive disease & $1.850(1.475-2.319)$ & $<.001$ & $1.522(1.264-1.833)$ & $<.001$ \\
\hline
\end{tabular}

\section{Discussion}

\section{Principal Findings}

Herein we used the SEER database to assess the role of histological subtypes in predicting the survival outcome among long-term survivors ( $\geq 5$ years) of advanced EOC. Our results indicate that ovarian cancer remains the primary cause of death among long-term ovarian cancer survivors. Moreover, patients with endometrioid, clear cell, and mucinous tumors showed a significant improvement in OCSS and OS compared to those with serous tumors. This study provides a unique opportunity to determine the characteristics of long-term survivors of advanced EOC.

There exist limited studies that have explored factors associated with long-term survival in EOC [6]. Such studies have reported that long-term survival is associated with various factors such as younger age at diagnosis, earlier clinicopathologic stage, absence of ascites, lower grade, earlier stage, nonserous histology, and lower CA125 levels [3-5,19,20]. In our study, we used a population-based cohort, and our results indicate that younger age, stage III disease, and nonserous cancers were associated with long-term survival in EOC. Our results add to the current knowledge on the prognostic factors for the long-term survivors of EOC. In addition, epidemiological factors such as low body mass index, not smoking, parity, and individual exhauster-scored conditions have been associated with long-term survival in EOC [5,21]. However, owing to the limitation of the SEER database, we could not identify these epidemiological factors.

In our previous studies, we have found a markedly increased mortality rate among patients with stage III-IV mucinous and clear cell cancers, but better survival among those with serous and endometrioid cancers [13,22]. These results concur with those reported by previous studies on stage III-IV EOC $[13,15,18,20,23,24]$. The aggressive behavior and impaired response to taxanes and platinum-based chemotherapy in the case of mucinous and clear cell carcinomas may be the core reason for these findings $[16,25,26]$. However, a study using the California Cancer Registry and including patients diagnosed with EOC between 1994 and 2001 reported that nonserous subtypes, including endometrioid, clear cell, and mucinous carcinomas, were significant predictors of long-term survival [3]; this study included patients with early-stage EOC, and it may hence not reflect the true long-term survival characteristics of patients with advanced-stage EOC.

The prognostic role of histological subtypes on the survival outcome among long-term survivors of advanced EOC has been explored by limited studies. A previous study by Son et al [27] reported that $91 \%$ of deaths occurred within 8 years, and that survival for 8 years may represent the prognostic inflection point for long-term survival in advanced EOC. However, only 11 patients survived for $>8$ years in the Son et al's [27] study. In our study, approximately $80 \%$ of ovarian cancer-related deaths occurred in $<5$ years. Among long-term survivors (who survived for $\geq 5$ years) ( $n=8050), 3874$ patients died of any causes during follow-up, and the majority of patients died from ovarian cancer-related disease, particularly those with the serous subtype. Our results suggest that although the peak of ovarian cancer-related deaths occurred within 5 years, intensive follow-up is required for long-term survivors.

Several studies, including ours, have indicated that the survival outcome of clear cell and mucinous cancers were significantly inferior to that of serous cancers in advanced-stage disease [12-16]. However, in this study, the OCSS and OS for clear cell and mucinous cancers were significantly longer than those for serous cancers in long-term survivors, suggesting that the prognostic effect of the histological subtype on EOC survival changed upon extensive follow-up. Therefore, surveillance options tailored depending on the nature of the histological subtype of EOC should be considered in future studies. The mechanisms underlying this more aggressive course in early, but not in long-term, outcomes for mucinous and clear cell cancers in advanced-stage disease have not been studied in detail. Failure to respond to chemotherapy could contribute to poorer survival in clear cell and mucinous cancers with respect to early outcome [28], while the risk of death in patients with 
clear cell and mucinous cancers may be significantly reduced upon extensive follow-up [3]. Genetic signatures could further our understanding of the potential biological differences between short- and long-term survivors. However, the current evidence lacks consistency, limiting the reproducibility and clinical use of molecular markers [6].

\section{Strengths and Limitations}

There were several limitations to our study. First, this is a retrospective study; hence, we could not exclude all potential selection biases. Second, information on chemotherapy regimens, administered dose, number of chemotherapy cycles, and completeness of chemotherapy were unavailable in the SEER database. Third, the size of residual tumors (before 2010), patterns of disease recurrence, and strategy of treatment after disease progression were also not recorded in the SEER database. Moreover, this database lacks a central review for histological subtype. On the other hand, the strengths of this study include its population-based design. This study involved a relatively large cohort of patients with EOC, with the data representing a real-world scenario. Furthermore, our results are expected to expand the current knowledge on the biological behavior of EOC by various histological subtypes after extensive follow-up. Further studies focusing on the prognostic factors regarding long-term survivors of EOC are needed.

\section{Conclusions}

In conclusion, our study suggests that ovarian cancer remains the primary cause of death among long-term ovarian cancer survivors. Moreover, the probability of death is significantly different among those with different histological subtypes of EOC. It is important for clinicians to individualize the surveillance program for long-term ovarian cancer survivors. Further studies using diverse cohorts are warranted to confirm our findings and expand our understanding.

\section{Acknowledgments}

This work was supported by grants from the National Natural Science Foundation of China (81802600), the Science and Technology Planning Projects of Xiamen Science \& Technology Bureau (3502Z20184016), and the Baise City Scientific Research and Technology Development Plan (20183008).

\section{Conflicts of Interest}

None declared.

\section{References}

1. Baldwin LA, Huang B, Miller RW, Tucker T, Goodrich ST, Podzielinski I, et al. Ten-year relative survival for epithelial ovarian cancer. Obstet Gynecol 2012 Sep;120(3):612-618. [doi: 10.1097/AOG.0b013e318264f794] [Medline: 22914471]

2. Gockley A, Melamed A, Bregar AJ, Clemmer JT, Birrer M, Schorge JO, et al. Outcomes of Women With High-Grade and Low-Grade Advanced-Stage Serous Epithelial Ovarian Cancer. Obstet Gynecol 2017 Mar;129(3):439-447 [FREE Full text] [doi: 10.1097/AOG.0000000000001867] [Medline: 28178043]

3. Cress RD, Chen YS, Morris CR, Petersen M, Leiserowitz GS. Characteristics of Long-Term Survivors of Epithelial Ovarian Cancer. Obstet Gynecol 2015 Sep;126(3):491-497 [FREE Full text] [doi: 10.1097/AOG.0000000000000981] [Medline: 26244529]

4. Akeson M, Jakobsen AM, Zetterqvist BM, Holmberg E, Brännström M, Horvath G. A population-based 5-year cohort study including all cases of epithelial ovarian cancer in western Sweden: 10-year survival and prognostic factors. Int $\mathbf{J}$ Gynecol Cancer 2009 Jan;19(1):116-123. [doi: 10.1111/IGC.0b013e3181991b13] [Medline: 19258952]

5. Kim SJ, Rosen B, Fan I, Ivanova A, McLaughlin JR, Risch H, et al. Epidemiologic factors that predict long-term survival following a diagnosis of epithelial ovarian cancer. Br J Cancer 2017 Mar 28;116(7):964-971 [FREE Full text] [doi: 10.1038/bjc.2017.35] [Medline: 28208158]

6. Hoppenot C, Eckert MA, Tienda SM, Lengyel E. Who are the long-term survivors of high grade serous ovarian cancer? Gynecol Oncol 2018 Jan;148(1):204-212. [doi: 10.1016/j.ygyno.2017.10.032] [Medline: 29128106]

7. Kurman RJ, Carcangiu ML, Herrington CS. WHO Classification of Tumours of Female Reproductive Organs. Lyon: IARC Press; 2014.

8. McCluggage WG. Morphological subtypes of ovarian carcinoma: a review with emphasis on new developments and pathogenesis. Pathology 2011 Aug;43(5):420-432. [doi: 10.1097/PAT.0b013e328348a6e7] [Medline: 21716157]

9. McMeekin DS, Burger RA, Manetta A, DiSaia P, Berman ML. Endometrioid adenocarcinoma of the ovary and its relationship to endometriosis. Gynecol Oncol 1995 Oct;59(1):81-86. [doi: 10.1006/gyno.1995.1271] [Medline: 7557621]

10. Fleming ST, Kimmick GG, Sabatino SA, Cress RD, Wu XC, Trentham-Dietz A, Patterns of Care Study Group. Defining care provided for breast cancer based on medical record review or Medicare claims: information from the Centers for Disease Control and Prevention Patterns of Care Study. Ann Epidemiol 2012 Nov;22(11):807-813. [doi: 10.1016/j.annepidem.2012.08.001] [Medline: 22948184]

11. Okamoto A, Glasspool RM, Mabuchi S, Matsumura N, Nomura H, Itamochi H, et al. Gynecologic Cancer InterGroup (GCIG) consensus review for clear cell carcinoma of the ovary. Int J Gynecol Cancer 2014 Nov;24(9 Suppl 3):S20-S25. [doi: 10.1097/IGC.0000000000000289] [Medline: 25341576] 
12. Zhou J, Zhang WW, Zhang QH, He ZY, Sun JY, Chen QH, et al. The effect of lymphadenectomy in advanced ovarian cancer according to residual tumor status: A population-based study. Int J Surg 2018 Apr;52:11-15 [FREE Full text] [doi: 10.1016/j.ijsu.2018.02.006] [Medline: 29432972]

13. Zhou J, Wu SG, Wang J, Sun JY, He ZY, Jin X, et al. The Effect of Histological Subtypes on Outcomes of Stage IV Epithelial Ovarian Cancer. Front Oncol 2018;8:577 [FREE Full text] [doi: 10.3389/fonc.2018.00577] [Medline: 30564556]

14. Oliver KE, Brady WE, Birrer M, Gershenson DM, Fleming G, Copeland LJ, et al. An evaluation of progression free survival and overall survival of ovarian cancer patients with clear cell carcinoma versus serous carcinoma treated with platinum therapy: An NRG Oncology/Gynecologic Oncology Group experience. Gynecol Oncol 2017 Nov;147(2):243-249 [FREE Full text] [doi: 10.1016/j.ygyno.2017.08.004] [Medline: 28807367]

15. Mackay HJ, Brady MF, Oza AM, Reuss A, Pujade-Lauraine E, Swart AM, Gynecologic Cancer InterGroup. Prognostic relevance of uncommon ovarian histology in women with stage III/IV epithelial ovarian cancer. Int J Gynecol Cancer 2010 Aug;20(6):945-952. [doi: 10.1111/IGC.0b013e3181dd0110] [Medline: 20683400]

16. Ho CM, Huang YJ, Chen TC, Huang SH, Liu FS, Chang Chien CC, et al. Pure-type clear cell carcinoma of the ovary as a distinct histological type and improved survival in patients treated with paclitaxel-platinum-based chemotherapy in pure-type advanced disease. Gynecol Oncol 2004 Jul;94(1):197-203. [doi: 10.1016/j.ygyno.2004.04.004] [Medline: 15262142]

17. Hess V, A'Hern R, Nasiri N, King DM, Blake PR, Barton DP, et al. Mucinous epithelial ovarian cancer: a separate entity requiring specific treatment. J Clin Oncol 2004 Mar 15;22(6):1040-1044. [doi: 10.1200/JCO.2004.08.078] [Medline: 15020606]

18. Kaern J, Aghmesheh M, Nesland JM, Danielsen HE, Sandstad B, Friedlander M, et al. Prognostic factors in ovarian carcinoma stage III patients. Can biomarkers improve the prediction of short- and long-term survivors? Int J Gynecol Cancer 2005;15(6):1014-1022 [FREE Full text] [doi: 10.1111/j.1525-1438.2005.00185.x] [Medline: 16343177]

19. SEER*Stat Software. National Cancer Institute: Surveillance, Epidemiology, and End Results Program. URL: https://seer. cancer.gov/seerstat/ [accessed 2021-10-28]

20. Kotsopoulos J, Rosen B, Fan I, Moody J, McLaughlin JR, Risch H, et al. Ten-year survival after epithelial ovarian cancer is not associated with BRCA mutation status. Gynecol Oncol 2016 Jan;140(1):42-47. [doi: 10.1016/j.ygyno.2015.11.009] [Medline: 26556769]

21. Clarke CL, Kushi LH, Chubak J, Pawloski PA, Bulkley JE, Epstein MM, et al. Predictors of Long-Term Survival among High-Grade Serous Ovarian Cancer Patients. Cancer Epidemiol Biomarkers Prev 2019 May;28(5):996-999 [FREE Full text] [doi: 10.1158/1055-9965.EPI-18-1324] [Medline: 30967418]

22. Wu SG, Li FY, Lei J, Hua L, He ZY, Zhou J. Histological Tumor Type is Associated with One-Year Cause-Specific Survival in Women with Stage III-IV Epithelial Ovarian Cancer: A Surveillance, Epidemiology, and End Results (SEER) Database Population Study, 2004-2014. Med Sci Monit 2020 Feb 02;26:e920531 [FREE Full text] [doi: 10.12659/MSM.920531] [Medline: 32008036]

23. Tothill RW, Tinker AV, George J, Brown R, Fox SB, Lade S, Australian Ovarian Cancer Study Group, et al. Novel molecular subtypes of serous and endometrioid ovarian cancer linked to clinical outcome. Clin Cancer Res 2008 Aug 15;14(16):5198-5208 [FREE Full text] [doi: 10.1158/1078-0432.CCR-08-0196] [Medline: 18698038]

24. Chang LC, Huang CF, Lai MS, Shen LJ, Wu FL, Cheng WF. Prognostic factors in epithelial ovarian cancer: A population-based study. PLoS One 2018;13(3):e0194993 [FREE Full text] [doi: 10.1371/journal.pone.0194993] [Medline: 29579127]

25. Sugiyama T, Kamura T, Kigawa J, Terakawa N, Kikuchi Y, Kita T, et al. Clinical characteristics of clear cell carcinoma of the ovary: a distinct histologic type with poor prognosis and resistance to platinum-based chemotherapy. Cancer 2000 Jun 01;88(11):2584-2589. [Medline: 10861437 ]

26. Takano M, Sugiyama T, Yaegashi N, Sagae S, Kuzuya K, Udagawa Y, et al. The impact of adjuvant chemotherapy for stage I clear cell carcinoma of the ovary: A retrospective Japan clear cell carcinoma study. JCO 2010 May 20;28(15_suppl):5052-5052. [doi: 10.1200/jco.2010.28.15 suppl.5052]

27. Son JH, Kong TW, Paek J, Song KH, Chang SJ, Ryu HS. Clinical characteristics and prognostic inflection points among long-term survivors of advanced epithelial ovarian cancer. Int J Gynaecol Obstet 2017 Dec;139(3):352-357. [doi: 10.1002/ijgo.12315] [Medline: 28857180]

28. Nakayama K, Takebayashi Y, Nakayama S, Hata K, Fujiwaki R, Fukumoto M, et al. Prognostic value of overexpression of p53 in human ovarian carcinoma patients receiving cisplatin. Cancer Lett 2003 Mar 31;192(2):227-235. [doi: 10.1016/s0304-3835(02)00686-9] [Medline: 12668287]

\section{Abbreviations}

AJCC: American Joint Committee on Cancer

EOC: epithelial ovarian cancer

HR: hazard ratio

OCSS: ovarian cancer-specific survival

OS: overall survival 
SEER: Surveillance, Epidemiology, and End Results

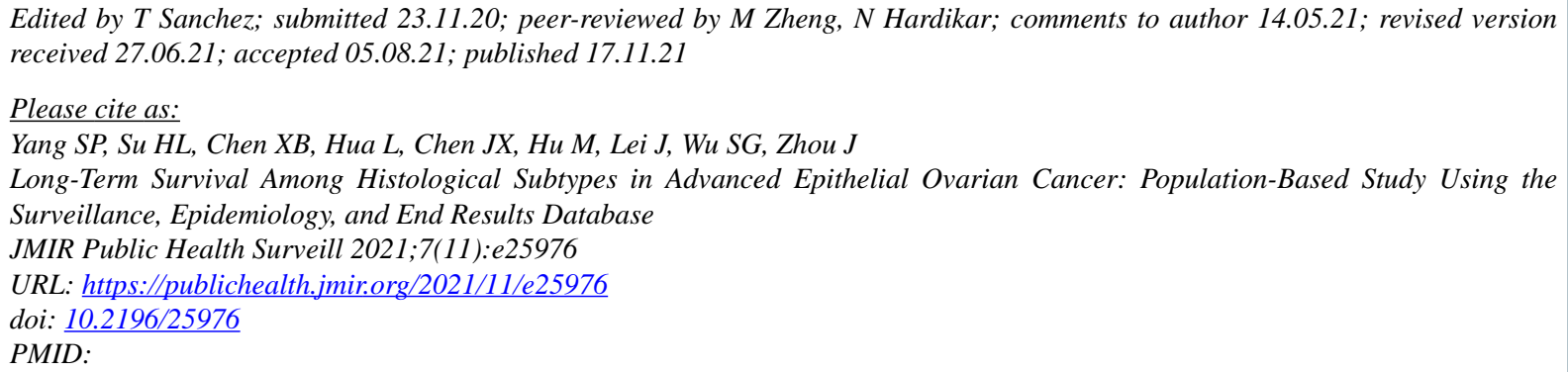

(C)Shi-Ping Yang, Hui-Luan Su, Xiu-Bei Chen, Li Hua, Jian-Xian Chen, Min Hu, Jian Lei, San-Gang Wu, Juan Zhou. Originally published in JMIR Public Health and Surveillance (https://publichealth.jmir.org), 17.11.2021. This is an open-access article distributed under the terms of the Creative Commons Attribution License (https://creativecommons.org/licenses/by/4.0/), which permits unrestricted use, distribution, and reproduction in any medium, provided the original work, first published in JMIR Public Health and Surveillance, is properly cited. The complete bibliographic information, a link to the original publication on https://publichealth.jmir.org, as well as this copyright and license information must be included. 